\title{
Representações sociais da cocaína: estudo comparativo entre universitários das áreas de saúde e jurídica
}

\section{Social representations of cocaine: a comparative study among undergraduate students from Health Science and Law areas}

\author{
Ludgleydson Fernandes de ARAÚJO \\ Bernard GONTIÉS ${ }^{\dagger}$ in memoriam \\ JonsOS NUNES JÚNIOR
}

\begin{abstract}
Resumo
Este estudo investigou as representações sociais da cocaína entre estudantes, em final de curso, da área de ciências da saúde e jurídica da Universidade Federal da Paraíba. Participaram cem estudantes, a maioria do sexo feminino (55\%), com média de idade de 27 anos. Foi utilizada entrevista semi-estruturada, aplicada individualmente, gravada mediante a permissão dos respondentes, para preservar o anonimato. Utilizou-se, para categorização dos dados, a análise de conteúdo temática de Bardin. Verificou-se que as representações estão ancoradas na identificação e pertença profissional dos universitários. Os estudantes de direito objetivaram suas representações sociais da cocaína na esfera legal e social. Os universitários de saúde objetivaram suas representações em aspectos relacionados ao tratamento e conseqüências orgânicas. Denota-se a necessidade da formulação de estratégias que sirvam de subsídios na formação de profissionais, nas suas práticas futuras de intervenção, de acordo com a necessidade dos usuários de drogas e seus familiares, bem como na promoção em saúde.
\end{abstract}

Unitermos: cocaína; representações sociais; estudantes universitários.

\begin{abstract}
This study broached social representations among undergraduate students from Health Science and Law of Universidade Federal da Paraiba. A hundred students from both areas took part in it. They were the majority female (55\%), whose age average was about 27. Semi-structured interview was used, applied individually and recorded, with participants' allowance Data categorizing was made through Bardin Thematic Subject Analysis. According to this study, the representations are anchored on identification and professional belongings of these academic students. When researched areas were compared, Law students presented cocaine social representations related to the legal and social ambit, while the students from Health Science area focused the treatment and organic consequences. Guidelines must be developed in order to provide strategies support to these future professionals in their intervention practices, It proposes implementation of health policies contemplating prevention of the abusive use of licit and illicit drugs.
\end{abstract}

Uniterms: cocaine; social representations; collegestudents.

reve

1 Universidade Federal de Piauí, Departamento de Psicologia. Av. São Sebastião, 2819, Campus Ministro Reis Veloso, 64202-020, Parnaíba, PI, Brasil. Correspondência para/Correspondence to: L.F. ARAÚJO. E-mail: <ludgleydson@yahoo.com.br>.

2 Universidade Federal da Paraíba, Departamento de Psicologia, Programa de Pós-Graduação em Psicologia Social. João Pessoa, PB, Brasil.

Agradecimento: os autores agradecem o apoio financeiro do Conselho Nacional de Pesquisa e Desenvolvimento. 
A cocaína é uma droga relativamente recente entre os tipos de substâncias psicoativas utilizadas pelo homem ao longo dos tempos. É extraída da planta da coca (Erytroxylus coca), que faz parte da cultura Inca; é anterior à chegada dos espanhóis na região andina, sendo comum entre os nativos daquela localidade mascar folhas da coca, o coquear, com o intuito de aumentar a resistência física, diminuir a fadiga e o apetite, além de permitir suportar as elevadas altitudes (Duarte, 1980; Graeff, 1989; Marques, 2004).

A cocaína insere-se entre as substâncias utilizadas em diversos contextos da vida em sociedade. Bucher (1992) advoga que a droga, na atualidade, é comumente associada ao sucesso profissional, no meio artístico, entre músicos, profissionais dos meios midiáticos de um modo geral, e do cinema, como também no meio empresarial, político, entre executivos e diplomatas.

O presente estudo aborda as representações sociais da cocaína elaboradas por universitários concluintes de duas áreas do conhecimento (saúde e jurídica). A relevância social e acadêmica dessa investigação tem como escopo o fato de os alunos serem futuros profissionais que poderão atuar, no âmbito da prevenção e promoção em saúde, com o intuito de diminuir o uso abusivo da cocaína nos diferentes níveis sociais.

A cocaína é uma sustância psicoativa pertencente às chamadas drogas estimulantes que alteram o funcionamento do cérebro, deixando-o mais ativado. Atua no sistema nervoso central (SNC), potencializando a neurotransmissão catecolaminérgica que funciona como um agente reforçador nas sinapses dopaminérgicas das vias ascendentes mesolímbicas e mesocorticais (Balster, 1997; Centro de Información Y Educación del Abuso de Drogas - Cedro, 1987; Oliveira, 1988).

As vias de administração da cocaína são a intranasal, por inalação, e a introvenosa, uma vez que o cloridrato é solúvel em água. O uso abusivo de cocaína por insuflação nasal pode gerar irritação da mucosa nasal, sinusite e perfuração do septo. A droga pode provocar alucinações visuais, auditivas e táteis (sensação de insetos e ponta de agulha, por exemplo) e idéias de 316 perseguição (Oliveira, 1988).
Bucher (1992) argumenta que os rituais da cocaína são em geral solitários, e que são associados à prática não marginalizante, tendo em vista que a substância psicoativa insere-se entre usuários de classe social privilegiada, quando comparada a drogas como álcool, solventes, maconha, que possuem inserção maior nas camadas populares, devido, sobretudo, à acessibilidade econômica e social.

O uso continuado da cocaína pode provocar os seguintes efeitos em médio prazo: sentimento generalizado de aumento da energia vital, da sensibilidade e do otimismo; diminuição da agitação, irritabilidade e ansiedade, hiperexcitabilidade, insônia, lassidão; modificações na capacidade de atenção e percepção, além de causar problemas orgânicos, como a ulceração das mucosas nasais (Bergeret \& Leblanc, 1991; Bucher, 1992; Graeff, 1989).

Uma das conseqüências freqüentes do consumo da cocaína é o surgimento de convulsões, principalmente do tipo tônico-clônicas (semelhante àquelas da epilepsia), o aumento da temperatura corpórea, que pode atingir mais de $42^{\circ}$, provocando a morte por hipertemia. Psicologicamente, o usuário pode ser acometido de depressão intensa, com risco de suicídio, desmotivação, sonolência, irritabilidade crônica, ansiedade e psicose paranóide (o indivíduo tem certeza que está sendo perseguido). É freqüente, também, infecção de pele (injeções contaminadas), infecção na válvula cardíaca, AIDS e hepatite (Balster, 1997, Secretaria Nacional Antidrogas - Senad, 2001).

É válido mencionar que as conseqüências apresentadas não são uma regra geral para os usuários da cocaína; há uma série de fatores concernentes à personalidade, as expectativas, ao ambiente social, ao estado emocional, à qualidade da droga, que, conjuntamente, desencadearão possíveis conseqüências na vida do usuário.

A demanda por utilização de substâncias psicoativas aumentou significativamente nas últimas décadas, constatação evidenciada pelos meios de comunicação e relatórios de instituições nacionais e internacionais. A oferta cresceu na mesma proporção, pois se tem mostrado um negócio rentável e de controle por parte de grupos (United National Organization, 2000). Não obstante o consumo de drogas tem ligações nas diversas esferas da sociedade, sendo algo complexo que 
envolve uma série de fatores políticos, econômicos, culturais e sociais a serem considerados nas investigações científicas para seu melhor entendimento.

Diante dessas premissas, optou-se por investigar a cocaína à luz da teoria das representações sociais (RS), tendo em vista a elaboração de um conhecimento prático e compartilhado por grupos sociais de pertença, que neste estudo são os universitários das ciências da saúde e jurídica da Universidade Federal da Paraíba (UFPB), cursando o último semestre de seus respectivos cursos.

\section{Aspectos teóricos}

A teoria das RS é elaborada nas relações interpessoais e intergrupais da vida cotidiana, sendo um saber do senso comum, construído através dos valores, atitudes, símbolos e crenças compartilhadas por um grupo social de pertença ou afiliação. As RS permitem a interpretação da realidade, construída através de idéias e imagens simbólicas peculiares a uma determinada realidade sócio-histórica e cultural (Moscovici, 2003).

Para Jodelet (2001), a representação social é uma construção e uma expressão do ator social ou de um grupo, que se apóia em valores, saberes, atitudes, opiniões, atribuindo significações, estabelecendo uma relação de simbolização e de interpretação, buscando uma definição ao objeto representado.

Para compreender melhor o funcionamento do comportamento humano, e o modo como os atores sociais se agrupam, deve-se considerar, conjuntamente, os afetos, as condutas, a organização, a sistematização de como eles compartilham crenças, atitudes, valores, perspectivas futuras e experiências sociais (Moscovici, 2003).

Assim, a representação social da cocaína, que faz parte do cotidiano social, recebe significados de acordo com os grupos de pertença e do contexto social no qual se encontram inseridos. Além disso, esses significados são resultantes da interação entre o senso comum e o conhecimento erudito, existindo uma relação de influência mútua e permanente entre os dois universos, que resulta numa diversidade de significados que circulam, através dos meios de comunicação formais e informais, assimilados e reelaborados socialmente.
A visão coletiva de que a representação social é vista como um processo público de criação, elaboração, difusão e mudança do conhecimento compartilhado no discurso cotidiano dos grupos sociais (Doise, 1990; Jodelet, 2001; Moscovici, 1984) é que foi utilizada no desenvolvimento deste estudo: "representação socialé compreendida como a elaboração de um objeto social pela comunidade com o propósito de conduzir-se e comunicar-se" (Moscovici, 1984, p.251).

Na elaboração das RS faz-se necessária a contribuição de dois fatores: a objetivação e a ancoragem, que são responsáveis pela interpretação e pela atribuição de significados do objeto social, neste estudo, o uso da cocaína. Para Moscovici, esses fatores são condições sine qua non, pois ambos colaboram com a maneira como o social transforma um conhecimento em representação e a maneira como essa transforma o social, indicando a interdependência entre a atividade psicológica e suas condições sociais.

A objetivação transforma uma abstração em algo concreto, é responsável pela aproximação do que é estranho em familiar. É por meio desse processo que os elementos adquirem materialidade e se tornam expressões de uma realidade vista como natural. A ancoragem é o processo da inserção de um conhecimento, enquanto quadro de referência, a partir de experiências e esquemas de pensamentos já estabelecidos sobre o objeto em estudo.

A inserção das drogas lícitas e ilícitas na vida cotidiana de diferentes segmentos sociais e as discussões que vêm suscitando nas pautas de políticas públicas de saúde e científicas justificam-se pelas conseqüências nefastas que o uso das substâncias acarreta à sociedade, ocasionando um sofrimento que interfere, significativamente, na diminuição da qualidade de vida, independentemente da faixa etária, classe socioeconômica, cultura, raça e espaço geográfico (Araújo, 2005; Bastos, 2003; Coutinho, Araújo \& Gontiès, 2004; Flores \& Luis, 2004; Gontiès \& Araújo, 2003; Pereira, 2002).

Dessa forma, a representação acerca das drogas, por parte dos universitários, é muito importante, uma vez que serão determinantes de suas práticas, pois segundo Andrade (2003), são eles que vão coordenar e gerenciar, num futuro próximo, esse fator que afeta tanto 
o indivíduo como sua família. Espera-se, portanto, que suas ações futuras sejam direcionadas a uma intervenção multidisciplinar, visando contribuir com a promoção e a prevenção da saúde.

O objeto investigativo da presente pesquisa utiliza-se das representações sociais, uma vez que a teoria nos permite conhecer, nas práticas sociais e comunicações dos atores, no caso, os estudantes de fim de curso das áreas das ciências da saúde e jurídicas, como esses grupos sociais articulam suas representações acerca da cocaína.

\section{Método}

\section{Participantes}

Cem estudantes concluintes dos cursos das áreas de ciências jurídicas (50) e da saúde (50) foram os participantes. A escolha da amostra foi aleatória, do tipo não probabilística (por conveniência) e acidental, de ambos os sexos (45\% masculino e 55\% feminino), com média (M) de idade de 27 anos (desvio-padrão (DP)= 2,74). Tendo em vista a randomização da amostra, optou-se por não considerar as diferenças de gênero e idades na estruturação dos grupos. É válido mencionar que, para participação na presente investigação, fazia-se necessário estar no último período das respectivas áreas do conhecimento, uma vez que Lacerda (2001) aponta que é nessa fase que o universitário se encontra mais identificado com sua futura profissão.

\section{Instrumentos}

Na coleta de dados, foram utilizadas entrevistas semi-estruturadas, divididas em duas partes: a primeira, constituída de itens referentes à identificação sociodemográfica dos participantes, definindo o seu perfil; e a segunda, composta de perguntas que foram realizadas, na ordem a seguir: o que você sabe acerca da cocaína? Quais as causas do uso da cocaína? As formas de tratamento do usuário? Quais as conseqüências do uso da cocaína?

O roteiro de entrevista foi elaborado previamente, tendo como pressupostos os objetivos da pesquisa e o estado atual da arte. Assim, realizou-se 318 um estudo-piloto com o intuito de verificar a boa adequação do instrumento; verificada a validade semântica do instrumento, efetuou-se, em seguida, o estudo definitivo.

\section{Procedimentos}

Para aplicação do instrumento, inicialmente, foram contatadas as coordenações dos cursos com o intuito de obter a listagem das turmas concluintes, para, posteriormente, verificar a disponibilidade dos universitários para participação nessa pesquisa. As entrevistas foram realizadas de forma individual, por dois pesquisadores previamente treinados e qualificados (a fim de minimizar os vieses de respostas e a desejabilidade social dos participantes), em salas da própria universidade, que no momento da sua efetivação estivessem desocupadas, com o intuito de não prejudicar a qualidade do material gravado. 0 tempo de aplicação foi, em média, de 40 minutos, para que cada participante respondesse ao instrumento.

Inicialmente, os estudantes foram contatados pelos pesquisadores, ocasião em que eram explicitadas todas as questões referentes à pesquisa, levando-se em consideração: o objetivo da pesquisa, a necessidade de estar cursando o último semestre e de gravar a entrevista, garantido o anonimato e a preservação da identidade dos participantes. É válido mencionar que não houve a recusa de nenhum estudante para participar de forma voluntária da pesquisa. Foram respeitadas todas as questões éticas elencadas na resolução da CNS/MS n¹96/96, que rege pesquisas envolvendo seres humanos.

No que se refere à análise dos dados desta pesquisa, utilizou-se a análise de conteúdo temática (Bardin, 1977), cujo objetivo é compreender o sentido das comunicações e suas significações explícitas e/ou ocultas. Seu procedimento visa ainda obter a sistematização e descrição do conteúdo das mensagens que permitem a inferência de conhecimentos relativos às condições de produção/recepção (variáveis inferidas), analisados quantitativamente por meio da análise das freqüências e percentuais. A análise das unidades temáticas, por meio da técnica, pressupõe o desenvolvimento das seguintes etapas operacionais: constituição do corpus; leitura flutuante; composição das unidades de análise; codificação e recortes; 
categorização e descrição das categorias. Após a leitura flutuante do corpus e a emersão das categorias empíricas, elas foram codificadas e validadas internamente por três pesquisadores-juízes que trabalham com essa técnica.

\section{Resultados}

As representações sociais acerca da cocaína, elaboradas pelos universitários das duas áreas de conhecimento com base no material coletado pelas entrevistas e ponderado pela análise temática de conteúdo, resultaram em cinco categorias empíricas e vinte e duas subcategorias.

Os resultados são apresentados em categorias e subcategorias, com suas respectivas freqüências simples das unidades de análise. Contudo faz-se necessário mencionar que algumas subcategorias, cujo valor foi zero, são apresentadas, uma vez que esta pesquisa objetiva comparar os resultados entre os universitários de saúde e direito. Dessa forma, a ausência ou presença dos valores das subcategorias serão discutidas, a posteriori, à luz do estado da arte, assim como dos objetivos propostos.

Quanto às representações sociais da cocaína, denota-se que a subcategoria mais enfatizada pelos estudantes de saúde foi estimulante do sistema nervoso central, com 36\%, seguida de alucinógeno, com 32\% e base de anestésicos, com 13\%. Quanto aos estudantes de direito, a subcategoria que apresentou maior percentual foi droga, com 55\%, seguida por derivado da coca (16\%) e alucinógeno (28\%).

Quanto às conseqüências na vida dos usuários de cocaína, denota-se, entre os universitários de saúde, maior destaque para a subcategoria de familiar, com 37\%; social, com 14\% e profissional, com 49\%. As representações sociais apreendidas entre os universitários de direito, na subcategoria social foi 61\%, familiar 25\% e conseqüências na esfera profissional 14\%.

No que se refere à terceira categoria - causas do uso da cocaína, houve a emersão de quatro subcategorias: fuga de problemas, prazer, curiosidade e influência de amigos. Os universitários da área da saúde apontam 44\% para fuga dos problemas, 28\% para prazer, $15 \%$ para curiosidade e 13\% na subcategoria referente à influência de amigos. Os estudantes de direito apontaram as seguintes causas do uso da maconha: $41 \%$ para fuga dos problemas, 28\% para prazer, 13\% para curiosidade e 18\% para influência de amigos.

A última categoria apreendida, refere-se às formas de tratamento dos usuários de cocaína, que foi subdividida em quatro subcategorias: tratamento médico, psicossocial, grupos de apoio e tratamento não especificado. Os estudantes de saúde apontaram 26\% para tratamento médico, 25\% para tratamento psicossocial, 37\% para tratamento não-especificado e 12\% para grupos de apoio. Já os estudantes da área jurídica revelaram 17\% para tratamento médico, 41\% para tratamento psicossocial e $29 \%$ para grupos de apoio.

\section{Discussão}

Este estudo parte do propósito de compreender as representações sociais de universitários das ciências da saúde e jurídicas acerca da cocaína, tendo em vista que eles serão os futuros profissionais que poderão contribuir para a prevenção do uso abusivo de drogas. As representações de cada um dos dois grupos serão discutidas a seguir, destacando-se os aspectos consensuais e aqueles que se diferenciaram em relação ao objeto pesquisado.

Pode-se verificar que as representações sociais pelos estudantes de saúde foram ancoradas em aspectos relacionados à farmacologia da cocaína - como: estimulante do sistema nervoso central e base de anestésicos (36\% e 13\%, respectivamente) - e às propriedades alucinógenas, com 32\%; ao passo que os estudantes da área jurídica ancoraram-se na subcategoria droga, com 55\% e alucinógena, com 28\%, como se pode verificar nas falas a seguir: ... a cocaína atua no cérebro, na região do sistemanervoso
central, ela também atua como base para anestésicos,
usado em anestésicos, causa alucinação nos usuários"
(Universitários da saúde).
... a cocaína éuma droga, éuma droga muito utilizada
em festas, éuma droga ilícita, seus efeitos alucinógenos
(Universitários de direito).
As propriedades farmacológicas pertinentes ao
entorpecente se devem à própria formação dos 
universitários (saúde). Nesse sentido, é consenso entre os estudiosos da toxicomania a classificação da cocaína como pertencente às drogas estimulantes do sistema nervoso central (Araújo, 2005; Cedro, 1987; Senad, 2001; Weinswig, 1973). De acordo com Bucher (1992), a cocaína é um estimulante poderoso que deixa o sistema nervoso central em alerta, comparável com um estado de alta tensão, contribuindo para uma série de iniciativas das quais dependem o seu desempenho, o seu sucesso, e sua carreira.

A Secretária Nacional Antidrogas (2001), por sua vez, aponta que a cocaína age nas células nervosas, alterando o funcionamento dos neurotransmissores dopaminérgicos e causando sensação de prazer por um período curto. Segundo Volpe, Tavares, Vargas e Rocha (1999), a cocaína pertence às drogas estimulantes do sistema nervoso central, podendo desencadear acidentes vasculares cerebrais. Assim, as representações sociais verificadas entre estudantes da saúde corroboram as afirmações presentes no estado da arte.

A propriedade alucinógena é algo incerto entre os estudiosos. Da literatura utilizada na presente pesquisa, pôde-se observar que apenas Cedro (1987) menciona efeitos alucinógenos da cocaína. Portanto esse fato aponta para a necessidade de pesquisas farmacológicas consoantes com as assertivas sobre as propriedades alucinógenas atribuídas pelos participantes da presente investigação.

A representação da cocaína como base para anestésicos teve com Karl Koller, um precursor, no seu uso como anestésico em cirurgias oftálmicas e de garganta. A cocaína foi largamente utilizada como propriedade anestésica no século XIX, com sua substituição, na medicina, em 1914, por drogas sintéticas, menos tóxicas e de efeito mais prolongado, a saber: novocaína, xilocaína ou lidocaína (Bergeret \& Leblanc, 1991; Bucher, 1992; Ferreira \& Martini, 2001; Senad, 2001).

\section{Conseqüências na vida dos usuários de cocaína \\ As representações dos universitários de saúde foram objetivadas como conseqüências nos aspectos profissionais (49\%) e familiares (37\%), ao passo que os 320 estudantes de direito objetivaram suas representações}

quanto às conseqüências na vida do usuário de cocaína nos aspectos sociais (61\%) e familiares (25\%). Denota-se que ambos os grupos pesquisados deram ênfase ao componente familiar. Infere-se que tal representação se deva a conseqüências que o uso abusivo de drogas pode provocar no contexto sociofamiliar e afetivo, como se pode verificar nas unidades temáticas das falas dos universitários:

\begin{abstract}
...pessoa que usa cocaína pode perder seu emprego ... o usuário vaiquerer utilizar droga no trabalho ... prejudica sua relação familiar/compromete sua vida familiar (Universitários da saúde).

... uso de cocaína pode trazer danos à vida social do usuário ... as relações de amizade são prejudicas pela cocaína, pode ficar sem a vida social ... a família podeter problemas econômicos e afetivos, pode destruir sua atuação profissional (Universitários de direito).
\end{abstract}

Bucher (1992) menciona que os usuários da cocaína elogiam as propriedades psicoativas existentes na droga, quais sejam: torná-los mais lúcidos; afinar a sensibilidade cinestésica; aumentar a concentração e o rendimento; eliminar o cansaço; reduzir medos e inibições; dispor de propriedades afrodisíacas, estimulando a atividade sexual e a sensação de potência.

O autor ainda salienta que a utilização da cocaína está comumente presente na classe artística e nos executivos bem-sucedidos devido às propriedades estimulantes concernentes ao alcalóide, associando-o ao sucesso e prestígio profissional. Tal fato não se coaduna com as representações das conseqüências na vida dos usuários de cocaína, conforme objetivadas pelos universitários, sobretudo da área de saúde.

Os usuários de substâncias psicoativas estão submetidos a uma série de fatores de riscos psicossociais que afetam o ambiente familiar, as relações interpessoais e afetivas, que, conjuntamente, podem contribuir para o aumento do consumo de drogas (Duvicq, Pereira \& Carvalho, 2004; Marques, 2004).

Nesse sentido, o uso abusivo de psicotrópicos rompe com o equilíbrio biopsicossocial do usuário, com possíveis alterações nas esferas orgânicas, psicológicas e sociais, que afetam a família em todos os seus aspectos, dificultando as relações afetivo-emocionais entre os diversos membros que compõem o núcleo familiar (Flores \& Luis, 2004). Esses fatores de risco são 
corroborados entre as representações sociais dos universitários de direito e saúde acerca das conseqüências no uso da cocaína.

\section{Causas do uso da cocaína}

Nessa categoria investigaram-se as causas do uso da cocaína pelos universitários das áreas de saúde e jurídica. Os universitários das duas áreas representaram, de forma consensual, as causas do uso da cocaína que se deve à fuga dos problemas, curiosidade e a busca de prazer.

De acordo com o Guia para a Família da SENAD (2001), uma das causas para o uso de drogas é a obtenção de prazer, como também uma tentativa de eliminar sentimentos de inadequação e baixa autoestima. Esses resultados corroboram os dados encontrados na presente pesquisa a respeito das causas do uso da cocaína, conforme exemplos a seguir:

...o usuário de cocaína procura fugir dos problemas, ele usa a droga para tentar sair dos problemas que está passando ... para sentir prazer da droga, pode serqueele use por curiosidade para saber como funciona (Universitários da saúde).

... éassim, para fugir dos problemas mesmo ..., pelo prazer que sente na cocaína ... pelo prazer que proporciona ... (Universitários de direito).

Em consonância com os resultados entre os estudantes paraibanos, Pereira (2002) verificou, junto aos universitários pernambucanos, que as principais causas do uso de drogas pela primeira vez revelou $80,2 \%$ por curiosidade, 0,9\% para esquecer problemas e 7,5\% por influência de amigos, semelhante aos dados encontrados entre os estudantes da UFPB. No que tange à justificativa de utilizar a droga na atualidade, a subcategoria mais realçada foi obter prazer $(78,0 \%)$, entre os estudantes pernambucanos.

De forma consoante com a presente pesquisa, Flores e Luis (2004) verificaram, entre universitários bolivianos, que um dos motivos para o uso de drogas é a influência de amigos, fato também denotado entre os universitários paraibanos.

\section{Formas de tratamento}

No que tange às formas de tratamento dos usuários de cocaína, denota-se que os universitários de saúde ancoraram suas representações no tratamento médico/orgânico, provavelmente devido à identificação profissional. Já os estudantes de direito destacaram o tratamento psicossocial e grupos de apoio como importantes no tratamento do usuário de cocaína. As representações sociais foram construídas por ambos os grupos, de acordo com a possível atuação profissional de cada área pesquisada.

Um fato que merece atenção diz respeito à subcategoria tratamento não-especificado, significativamente mencionada, sobretudo, pelos universitários de saúde. Tal fato é preocupante uma vez que os futuros profissionais, que têm como meta principal no exercício de sua profissão a promoção e prevenção em saúde, ainda não dispõem de estratégias de tratamento para os usuários de drogas. Infere-se que essa representação esteja ancorada na ausência de disciplinas nas grades curriculares dos cursos de saúde pesquisados que possibilitem e dêem oportunidade aos universitários de contatos com a temática das drogas, e com formas de intervenção e prevenção ao uso abusivo de substâncias psicoativas (Araújo, 2005; Coutinho, et al., 2004; Gontiès \& Araújo, 2003; Marques, 2004).

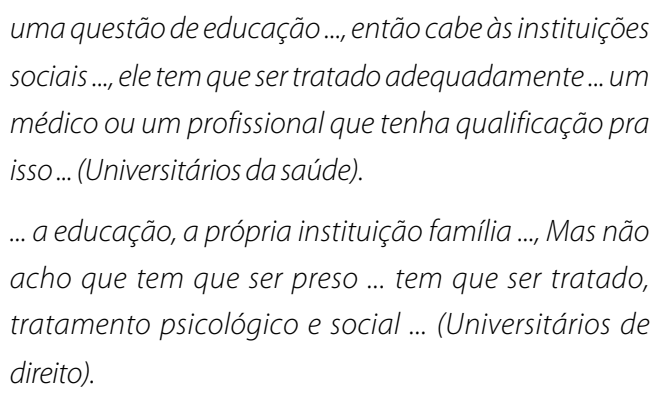
sociais ..., ele tem que ser tratado adequadamente... um médico ou um profissional que tenha qualificação pra isso... (Universitários da saúde).

... a educação, a própria instituição família ..., Mas não acho que tem que ser preso ... tem que ser tratado, tratamento psicológico e social ... (Universitários de direito).

As representações sociais do tratamento do usuário de cocaína, objetivada entre os universitários pesquisados, não se coadunam com a Portaria n 816/ 2002 do Ministério da Saúde, que regula o atendimento aos usuários dependentes de drogas e álcool em Centros de Atenção Psicossocial (CAPS-AD), dispondo de uma equipe interdisciplinar, com psicólogos, assistentes sociais, médicos, enfermeiros, cujo modelo preconiza uma abordagem holística ao tratamento do usuário de drogas. 


\section{Considerações Finais}

Esta pesquisa tentou compreender as representações sociais de universitários das ciências da saúde e jurídicas sobre cocaína, uma vez que, possivelmente, poderão lidar com a toxicomania e sua inserção em programas de intervenção aos usuários de drogas, educação preventiva em saúde e seus aspectos legais.

As representações sociais dos estudantes de saúde ancoraram-se num paradigma biomédico tradicional, tendo em vista a ênfase nas manifestações físicas e orgânicas, embasado majoritariamente no tratamento médico, ao passo que os de direito ancoraram suas representações sociais num paradigma ético, legal e moral, que preconiza o uso de drogas como ato transgressor e que requer intervenção baseada em sanções penais/legais, com medidas de caráter punitivo.

Observa-se, também entre os universitários pesquisados, que apenas os da área de saúde apontaram os conteúdos de disciplinas acadêmicas relacionadas às substâncias psicoativas como fonte de informações, apontando a necessidade premente da inclusão de disciplinas que disponibilizem debates e aprofundamentos do papel do profissional de saúde e do direito diante das drogas, bem como de sua intervenção na prevenção e promoção em saúde relacionados ao uso de entorpecentes.

Sugere-se que pesquisas futuras sejam realizadas no sentido de disponibilizar uma melhor compreensão do objeto (drogas), que por um longo espaço de tempo teve prioridade apenas em seu aspecto jurídico/policial, inserindo-se nos últimos anos em áreas como saúde pública, educação, psicologia social, antropologia, dentre outras.

A psicologia social, em particular, tem formulado microteorias acerca da mudança de atitudes, crenças, representações sociais, com o intuito de minimizar os estereótipos negativos acerca dos usuários de psicotrópicos, bem como a participação de psicólogos sociais, conjuntamente com outros profissionais de saúde, na formação de multiplicadores de informações sobre drogas nas escolas, nos programas de agentes comunitários de saúde e em comunidades com baixo

322 poder aquisitivo.
Espera-se que esta pesquisa possa contribuir, de forma parcimoniosa, para o melhor entendimento acerca das representações sociais da cocaína, como, também, vislumbrar as diversas facetas que compõem o conhecimento elaborado entre os universitários pesquisados, levando-se em consideração que o fenômeno das drogas é algo que perpassa a interdisciplinaridade, uma vez que cada área, com sua especificidade, pode contribuir para diminuir o uso abusivo de substâncias psicoativas na sociedade contemporânea.

\section{Referências}

Araújo, L. F. (2005). As drogas agindo no organismo humano. Jornal Mundo Jovem, 357:14.

Andrade, A. G. (2003). O uso de drogas nas universidades. Revista de Cultura-IMAE, 4 (9), 30-9.

Bastos, M. T. (2003). Combate ao narcotráfico. Revista de Cultura$-I M A E, 4(9), 6-11$.

Bardin, L. (1977). Análise de conteúdo. Lisboa: Edições 70.

Balester, R. L. (1997). Uso abusivo de drogas e de substâncias. InT. M. Brody, J. Larner, K. P. Minneman \& H. C. Neu. Farmacologia humana (pp.386-399). Rio de Janeiro: Guanabara.

Bergeret, J., \& Leblanc, J. (1991). Toxicomanias: uma visão muldisciplinar. Porto Alegre: Artes Médicas.

Bucher, R. (1992). Drogas e drogadição no Brasil. Porto Alegre: Artes Médicas.

Brasil. Ministério da Saúde, (2002). Portaria no 816 de 30 de abril de 2002. Dispõe sobre o Programa Nacional de Atenção Comunitária Integrada a Usuários de álcool e outras drogas. Diário Oficial da União, maio 3: seção 1, 29 30.

Centro de Información y Educación para la Prevención del Abuso de Drogas. (1987). Sobre la cocaína, sus derivadosy la marihuana. Lima: Perú.

Coutinho, M. P. L., Araújo, L. F., \& Gontiès, B. (2004). Uso da maconha e suas representações sociais: estudo comparativo entre universitários. Psicologia em Estudo, Maringá, 9 (3), 331-339.

Doise, W. (1990). Lês Représentations Sociales. In R. Ghiglione, C. Bonnet \& J. F. Richard (Orgs.). Traité de psychologie cognitive (Vol.3, pp.23-34). Paris: PUF.

Duarte, C. E. (1980). Toxicomanias. Jornal Brasileiro de Psiquiatria, 29 (6), 397-404.

Ducviq, C. G., Pereira, N. R., \& Carvalho, A M. P. (2004). O consumo de drogas lícitas e ilícitas por estudantes e fatores de proteção e riscos. Revista Latino-Americana de Enfermagem, 12 (número especial), 9-14.

Ferreira, P. E. M., \& Martini, R. K. (2001). Cocaína: lendas, história e abuso. Revista Brasileira de Psiquiatria, 23 (2), 96-99. 
Flores, I. E., \& Luis, M. A. V. (2004). Uso y actitudes relacionados a las drogas em las estudiantes de enfermería d ela Universidad Mayor de San Andrés. Revista Latino-Americana de Enfermagem, 12 (número especial), 1-8.

Gontiès, B., \& Araújo, L. F. (2003). Os aspectos legais da maconha no contexto universitário: um estudo das representações sociais. In M. P. L. Coutinho, A.S. Lima, M.L. Fortunato \& F.B. Oliveira (Orgs.). Representações sociais: abordagem interdisciplinar (pp.293-311). João Pessoa: EdUFPB.

Graeff, F. G. (1989). Drogas psicotrópicas e seu modo de ação. São Paulo: E.P.U.

Jodelet, D. (2001). Representações sociais. Rio de Janeiro: EdUERJ.

Lacerda, M. T. (2001). Representações sociais da homossexualidade. Dissertação de mestrado não-publicada, Universidade Federal da Paraíba, Alagoas.

Marques, A. C. P. R. (2004). Uma questão de foco. Disponível em http://www.abead.org.br /asp/popup_questao.asp (consultado em 29/11/2004).

Moscovici, S. (1984). Psycologie sociale. Paris: PUF.

Moscovici, S. (2003). Representações sociais: investigações em psicologia social. Petrópolis: Vozes.
United Nations Organizations. (2000). Global illicit drug trends. New York: United Nations.

Oliveira, E. M. L. P. (1988). Drogas e seus efeitos. In R. Bucher (Org.), As drogas e a vida: uma abordagem biopsicossocial (pp.15-23). São Paulo: EPU.

Pereira, R. C. (2002). O consumo de drogas entre universitários da UFRPE. Dissertação de mestrado não-publicada, Universidade Federal Rural de Pernambuco, Recife.

Secretaria Nacional Antidrogas. (2001). Conversando sobre cocaína e crack. Brasília: Senad.

Volpe, F. M., Tavares, A., Vargas, A.P. \& Rocha, P.R. et al. (1999). Vasculite cerebral e uso de cocaína e crack. Revista Brasileira de Psiquiatria, 21 (3), 30-35.

Weinswig, M. H. (1973). Use and misure of drugs subject to abuse. New York: Pegasus.

Recebido em: 5/8/2005

Versão final reapresentada em: 14/12/2005

Aprovado em: 2/8/2006 
